\title{
OPEN Ab initio study for molecular-scale adsorption, decomposition and desorption on AIN surfaces during MOCVD growth
}

\author{
Jiadai $\mathrm{An}^{1,2}$, Xianying Dai ${ }^{1,2}$, Runqiu Guo ${ }^{3}$, Lansheng Feng ${ }^{3}$ \& Tianlong Zhao ${ }^{1,2}$
}

Since AIGaN offers new opportunities for the development of the solid state ultraviolet (UV) luminescence, detectors and high-power electronic devices, the growth of AIN buffer substrate is concerned. However, the growth of AIN buffer substrate during MOCVD is regulated by an intricate interplay of gas-phase and surface reactions that are beyond the resolution of experimental techniques, especially the surface growth process. We used density-functional ab initio calculations to analyze the adsorption, decomposition and desorption of group-III and group-V sources on AIN surfaces during MOCVD growth in molecular-scale. For $\mathrm{AlCH}_{3}$ molecule the group-III source, the results indicate that $\mathrm{AICH}_{3}$ is more easily adsorbed on $\mathrm{AIN}(0001)$ than $(000 \overline{1})$ surface on the top site. For the group- $\mathrm{V}$ source decomposition we found that $\mathrm{NH}_{2}$ molecule is the most favorable adsorption source and adsorbed on the top site. We investigated the adsorption of group-III source on the reconstructed AIN (0001) surface which demonstrates that $\mathrm{NH}_{2}$-rich condition has a repulsion effect to it. Furthermore, the desorption path of group-III and group-V radicals has been proposed. Our study explained the molecular-scale surface reaction mechanism of AIN during MOCVD and established the surface growth model on AIN (0001) surface.

Since high-Al-content AlGaN can achieve a wide range of adjustable direct bandgap, high temperature and high pressure resistance and other properties, $\mathrm{AlGaN}$ has attracted much attention as a key material in the fields of solid state ultraviolet (UV) luminescence, detectors and high-power electronic devices ${ }^{1-4}$. Studies have shown that there is a large lattice mismatch and thermal mismatch between the AlGaN and sapphire substrate. Due to the mismatch there will generate some non-radiative composite center which affects the luminous efficiency of the material ${ }^{5-7}$. In order to reduce the problem caused by substrate mismatch, the AlN buffer substrate usually be used to grow high-Al-content AlGaN epitaxial film materials. Therefore, we need to study the growth mechanism of AlN to grow high-quality AlN layers firstly ${ }^{8-10}$.

The growth of high-quality AlN layers has been intensively performed by means of epitaxial growth, and the optimization of epitaxial growth condition is an important factor to improve crystal quality ${ }^{11-13}$. Theoretical studies on the epitaxial growth mechanisms of AlN are sparse and focus on the atomic and electronic structure ${ }^{13-16}$, and some surface growth mechanisms have been studied in atom-scale ${ }^{10,17-20}$, but the molecular-scale growth processes on AlN polar surfaces during epitaxial growth still remain unclear ${ }^{21,22}$. In this work, the adsorption, decomposition and desorption processes of group-III and group-V sources on AlN polar surfaces during MOCVD growth in molecular-scale were investigated to establish the initial growth model on the surface.

\section{Calculation modeling}

Due to gas-phase chemical reaction, the surface reaction precursors reaching high-temperature substrate are mainly $\mathrm{AlCH}_{3}$ molecules generated from decomposition of metallic organic compounds such as $\mathrm{Al}\left(\mathrm{CH}_{3}\right)_{3}$, which are used as the group-III sources to investigate the reaction process on AlN surface ${ }^{23}$. The models used for AlN $(0001)$ and AlN $(000 \overline{1})$ surfaces were $(2 \times 2)$ slab models with four AlN bilayers and are shown in Fig. 1 . The vacuum region above the surface was set to $20 \AA^{24,25}$. In order to maintain the crystal structure of the bulk AlN, the coordinates of the bottom four layers and the fictional $\mathrm{H}$ atom were fixed, which used $\mathrm{H}$ atoms with 0.75

${ }^{1}$ School of Microelectronics, Xidian University, Xi'an 710071, China. ${ }^{2}$ State Key Discipline Laboratory of Wide Bandgap Semiconductor Technologies, Xidian University, Xi'an 710071, China. ${ }^{3}$ School of Mechano-Electronic Engineering, Xidian University, Xi'an 710071, China. ${ }^{\varpi}$ email: xydai@xidian.edu.cn 


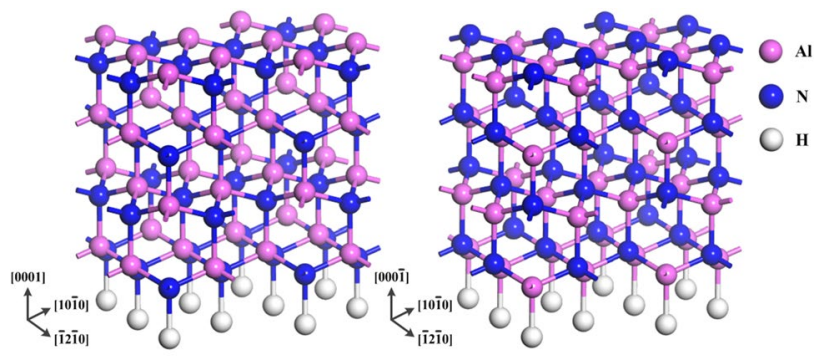

(a)

(b)

Figure 1. The models of $(2 \times 2)$ slab models with four AlN layers (a) AlN (0001) surface the top layer is $\mathrm{Al}$ atoms and (b) AlN (000) surface the top layer is $\mathrm{N}$ atoms. The bottom layer of these models is terminated with fictitious hydrogen atoms, where pink, blue and white spheres denote aluminum, nitrogen and hydrogen atoms, respectively.

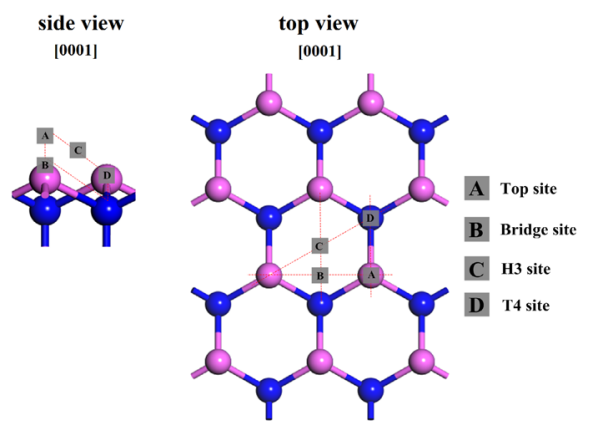

(a)

(b)

Figure 2. (a) Side-view and (b) Top-view of $(2 \times 2)$ slab model of the AlN (0001) surface. The signs show the adsorption sites for III-group and V-group sources, where pink and blue spheres denote aluminum and nitrogen atoms, respectively.

atomic number and 1.25 atomic number for AlN (0001) and AlN (0001) surfaces, respectively. While those of the top four layers were variable ${ }^{26}$.

The group-III and group-V sources were gradually moved from the vacuum space of the model to the adsorption sites shown in Fig. 2, and the adsorption energy was calculated for each case. In order to compare the stability of surface after adsorption, the surface formation energy was calculated using the chemical potential method $^{27-29}$. The van der Waals (vdW) dispersion interactions are a key ingredient for molecule adsorption. For the calculation, the density functional theory (DFT)-D2/D3 with a generalized gradient approximation (GGA) for the exchange correlation energy ${ }^{26,30,31}$. The function used was a revised Perdew-Burke-Ernzerh of function $(\mathrm{RPBE})^{26,32-35}$. The wave functions were expanded in terms of numerical basis sets. The real-space cutoff energy was set as $600 \mathrm{eV}$, and $6 \times 4 \times 2 \mathrm{k}$-point sampling was used. The accuracy of this setting is sufficient to meet the requirements of AlN geometric optimization and energy optimization. The calculations were carried out using the program package CASTEP ${ }^{36,37}$. The adsorption energy of molecules adsorbed on the surface of AlN can be obtained by the total energy difference:

$$
E_{a d}=E_{\text {total }}-E_{\text {molecules }}-E_{\text {slab }}
$$

where $E_{\text {total }}$ refers to the total energy of the optimized AlN layers with the adsorbed molecules. $E_{\text {molecules }}$ and $E_{\text {slab }}$ represent the energy of the molecules computed in the gas phase and the optimized slab of the AlN layers without adsorption, respectively ${ }^{32}$.

To study the desorption process of adsorbed molecules, we searched the transition states and found the most stable and the minimum energy by calculating reaction energy barrier used a LST/QST calculation method based on the transition state theory of DFT. During the deposition and growth on the surface of high temperature MOCVD, the reaction path direction was along the vertical direction to the growth surface (normal to the surface $)^{38,39}$. 


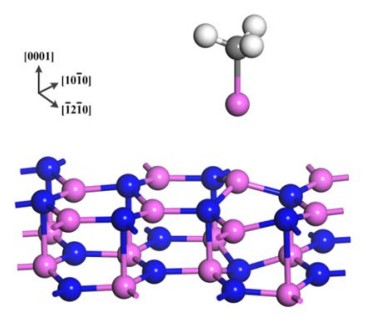

(a)

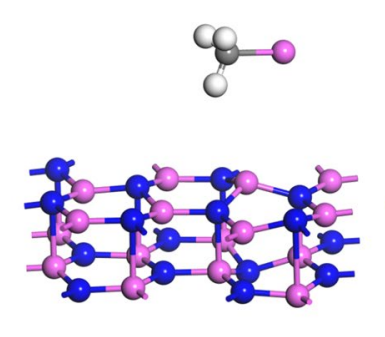

(b)

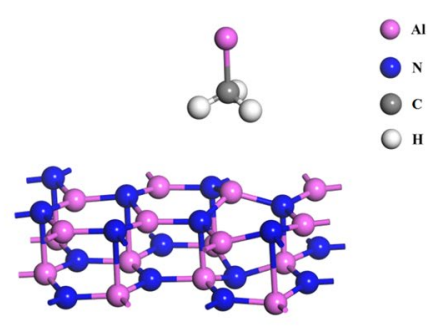

(c)

Figure 3. The configurations for $\mathrm{AlCH}_{3}$ molecule adsorption to the $\mathrm{AlN}$ (0001) surface; (a) $\mathrm{Al}$ atom faces to the surface, (b) $\mathrm{AlCH}_{3}$ molecule lies parallel to the surface and (c) $\mathrm{H}$ atom faces to the surface, where pink, blue and white spheres denote aluminum, nitrogen and hydrogen atoms, respectively.

\begin{tabular}{|l|l|l|l|l|l|}
\hline Layer & Initial site & Final site & $\boldsymbol{E}_{\boldsymbol{a d}}(\mathrm{eV})$ & $\boldsymbol{d}_{A l-\text { surf }}(\mathbf{\AA})$ & $\boldsymbol{\theta}($ degree $)$ \\
\hline \multirow{4}{*}{$\mathrm{AlCH}_{3}$ on the AlN (0001) surface } & Top & Top & -4.58 & 2.667 & 1.097 \\
\cline { 2 - 7 } & Bridge & Top & -0.21 & 2.732 & 51.049 \\
\cline { 2 - 7 } & h3 & Top & -0.319 & 2.720 & 73.192 \\
\cline { 2 - 7 } & t4 & Top & 0.135 & 3.002 & 49.201 \\
\hline \multirow{3}{*}{$\mathrm{AlCH}_{3}$ on the AlN $(000 \overline{1})$ surface } & Top & t4 & 4.764 & 1.182 & 48.442 \\
\cline { 2 - 7 } & Bridge & h3 & 3.562 & 1.172 & 20.754 \\
\cline { 2 - 7 } & h3 & h3 & 4.125 & 0.957 & 1.098 \\
\cline { 2 - 7 } & t4 & h3 & 3.341 & 1.165 & 74.075 \\
\hline
\end{tabular}

Table 1. Structure parameters, stable adsorption sites at $\mathrm{AlCH}_{3}$ adsorbed on the $\mathrm{AlN}(0001)$ and $\mathrm{AlN}(000 \overline{1})$ surfaces, and the corresponding adsorption energies. $E_{a d}$ represents the adsorption energy. $d_{A l-s u r f}$ represents the average distance of $\mathrm{Al}$ atom in $\mathrm{AlCH}_{3}$ with the topmost surface. $\theta$ represents the angle between the $\mathrm{C}-\mathrm{Al}$ bond and the topmost surface.

\section{Results and discussion}

Adsorption of group-III source on AIN surface. Firstly, the structures that group-III source adsorbed on the adsorption site on AlN (0001) and AlN (000) $\overline{1}$ ) surfaces (shown in Fig. 2) were optimized. In the case of $\mathrm{AlCH}_{3}$ molecule, three configurations can be considered, which are shown in Fig. 3. Geometry optimization was performed for these configurations and it was found that $\mathrm{AlCH}_{3}$ molecule adsorbed with the configuration which $\mathrm{Al}$ atom faces to surface.

Based on the surface structures, the calculation for the adsorption process was performed for $\mathrm{AlCH}_{3}$, and the results are shown in Table 1. On AlN (0001) surface, it was found that the minimum distance of $\mathrm{Al}$ atom in $\mathrm{AlCH}_{3}$ molecule with the topmost surface occurs in the case of top site with the value of $2.667 \AA$. For the angle between the $\mathrm{C}-\mathrm{Al}$ bond and the topmost surface, the top site with the value of 1.097 degree shows the smallest angle. And the adsorption energy of the top site was the lowest with the value of $-4.58 \mathrm{eV}$. The results indicated that $\mathrm{AlCH}_{3}$ will diffusion to the top site when it reaches on AlN (0001) surface. On the contrary, on the AlN $(000 \overline{1})$ surface, the adsorption energies of all the sites are positive, indicating that the adsorption process requires heat which is not stable.

The calculation of the potential-energy surfaces (PES) for $\mathrm{AlCH}_{3}$ molecules on the $2 \times 2 \mathrm{AlN}(0001)$ and AlN $(000 \overline{1})$ surfaces are shown as Fig. 4. The most stable adsorption site on AlN (0001) surface is located above the topmost surface $\mathrm{Al}$ atom which is the top site ((arrow in Fig. 4a). This results in the formation of an $\mathrm{Al}-\mathrm{Al}$ bond (bond length $2.66 \AA$ ) between $\mathrm{Al}$ atom in $\mathrm{AlCH}_{3}$ molecule and topmost surface $\mathrm{Al}$ atom. The adsorption energy $E_{a d}=-4.58 \mathrm{eV}$, corresponding to the energy gain to form an Al-Al bond. Similarly, the most stable adsorption site on the AlN $(000 \overline{1})$ surface is located above the center of the hexagonal structure on topmost surface which is the h3 site ((arrow in Fig. 4b). As shown in Fig. 4b, consistent with the adsorption energy calculated above, the adsorption energy of AlN $(000 \overline{1})$ surface is positive which indicates the adsorption process is not stable.

The adsorption of $\mathrm{AlCH}_{3}$ molecule on AlN (0001) surface is bound to be accompanied by the transfer of charge between atoms and the change of electronic structure. Therefore, the Mulliken charge population of the adsorbed particles and the topmost surface atoms is analyzed, and the results are shown in Table 2. Due to the three $\mathrm{H}$ atoms in $\mathrm{CH}_{3}$ are symmetrically distributed, the Mulliken charge population of one is listed only. As the electrons in the inner layer of an atom are stable, the $s$ and p orbitals in Table 2 show the outermost atomic orbitals. In Table 2, there is a slight change of the charge population numbers of $\mathrm{C}$ and $\mathrm{H}$ atoms before and after adsorption, while the charge population numbers of $\mathrm{s}$ and $\mathrm{p}$ orbitals of $\mathrm{Al}$ atom in $\mathrm{AlCH}_{3} \mathrm{molecule}_{\mathrm{and}} \mathrm{Al}$ atom on the top site of topmost surface changed greatly. The charge population of $\mathrm{s}$ and $\mathrm{p}$ orbitals of $\mathrm{Al}$ atom in $\mathrm{AlCH}_{3}$ molecule changed from 1.81 and 0.59 before adsorption to 1.52 and 0.70 after adsorption, the electron transfer number is 0.29 and 0.11 , respectively. Similarly, the electron transfer number of $s$ and $\mathrm{p}$ orbitals of $\mathrm{Al}$ 


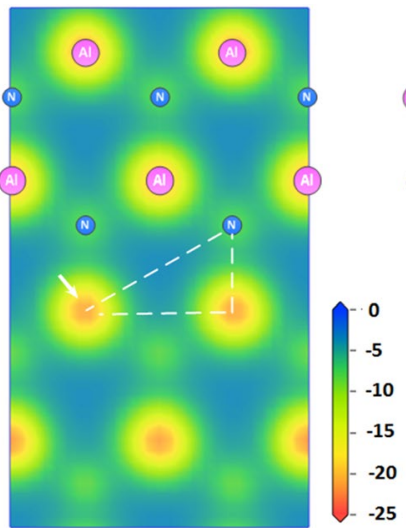

(a)

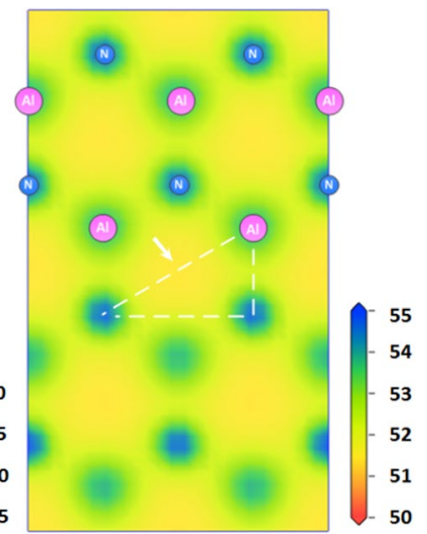

(b)

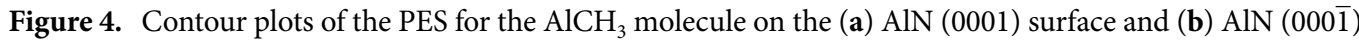
surface, the unit is $\mathrm{eV}$.

\begin{tabular}{|l|l|l|l|l|}
\hline & Atoms & $\mathbf{s}$ & $\mathbf{p}$ & Charge (e) \\
\hline \multirow{4}{*}{ Before adsorption } & $\mathrm{C}$ & 1.55 & 3.76 & -1.32 \\
\cline { 2 - 5 } & $\mathrm{H}$ & 0.76 & 0.00 & 0.24 \\
\cline { 2 - 5 } & $\mathrm{Al}$ & 1.81 & 0.59 & 0.60 \\
\cline { 2 - 5 } & $\mathrm{AlCH}_{3}$ & none & none & 0.00 \\
\cline { 2 - 5 } & $\mathrm{Al}_{\text {surf }}$ & 0.74 & 1.08 & 1.18 \\
\hline \multirow{4}{*}{ After adsorption (top site) } & $\mathrm{C}$ & 1.54 & 3.75 & -1.29 \\
\cline { 2 - 5 } & $\mathrm{H}$ & 0.76 & 0.00 & 0.24 \\
\cline { 2 - 5 } & $\mathrm{Al}$ & 1.52 & 0.70 & 0.78 \\
\cline { 2 - 5 } & $\mathrm{AlCH}_{3}$ & none & none & 0.22 \\
\cline { 2 - 5 } & $\mathrm{Al}_{\text {surf }}$ & 0.62 & 1.13 & 1.26 \\
\hline
\end{tabular}

Table 2. Mulliken charge population of each atoms in $\mathrm{AlCH}_{3}$ and $\mathrm{Al}$ atom on the top site of topmost surface before and after adsorption.

atom on the top site is 0.12 and -0.05 , respectively. Therefore, the adsorption of $\mathrm{AlCH}_{3}$ molecule on the AlN (0001) surface mainly depends on the interaction between the $\mathrm{s}$ and $\mathrm{p}$ orbitals of $\mathrm{Al}$ atom in $\mathrm{AlCH}_{3}$ molecule and the $\mathrm{Al}$ atom on the top site of topmost surface. The change of charge shows that the increase of positivity of $\mathrm{Al}$ atom in $\mathrm{AlCH}_{3}$ molecule after adsorption is greater than that in the $\mathrm{Al}$ atom on the top site, indicating that $\mathrm{Al}$ atom in $\mathrm{AlCH}_{3}$ loses electrons in the adsorption process, and the adsorption mechanism is that the adatoms transfer electrons to the surface atoms.

The results indicated that the adsorption energy and the stable adsorption site of group-III source $\mathrm{AlCH}_{3}$ molecule on AlN surface are affected by the topmost surface atoms, and the $\mathrm{AlCH}_{3}$ molecule is easier adsorbed on the top site of AlN (0001) surface which explained in theory why the epitaxial growth of AlN for devices has usually been grown along the [0001] direction.

Decomposition and adsorption of group-V sources on AIN surface. According to the above analysis, the AlN has been mainly grown along the [0001] direction, so of this part the growth surface is on AlN (0001) surface. First, the structures that $\mathrm{NH}_{\mathrm{n}}(\mathrm{n}=0-3)$ adsorbed on the adsorption sites on AlN (0001) surface (shown in Fig. 2) were optimized. The adsorption sites and adsorption energies for each adsorption species are shown in Table 3. From the calculations, it was shown that $\mathrm{NH}_{3}, \mathrm{NH}_{2}, \mathrm{NH}$ and $\mathrm{N}$ favorably were adsorbed on the top, top, bridge and 44 sites on AlN (0001) surface, respectively. It was found that the adsorption energy of $\mathrm{NH}_{3}$ is positive, and $d_{N-\text { surf }}$ and $\theta$ were the maximum with the value of $2.461 \AA$ and 0.069 degree which indicates the $\mathrm{NH}_{3}$ is not stable species. From the adsorption energy, $\mathrm{N}$ is the most favorable adsorption species. However, these adsorption energies were obtained on the assumption that $\mathrm{NH}_{2}, \mathrm{NH}$ and $\mathrm{N}$ were present in the vapor phase from the beginning. In addition, we should consider the decomposition of nitrogen sources under high temperature gas phase. Therefore, we calculated the energy required for the decomposition process of the repeated dehydrogenation from the $\mathrm{NH}_{3}$.

$$
\begin{aligned}
& N_{3}=N H_{2}+H \\
& N H_{2}=N H+H
\end{aligned}
$$




\begin{tabular}{|c|c|c|c|c|}
\hline Adsorption species & Adsorption site & $E_{a d}(\mathrm{eV})$ & $d_{N-\text { surf }}(\AA)$ & $\theta$ (degree) \\
\hline \multirow{4}{*}{$\mathrm{NH}_{3}$} & Top & 1.926 & 2.461 & 0.069 \\
\hline & Bridge & 2.876 & 3.121 & 0.122 \\
\hline & H3 & 2.012 & 2.975 & 0.091 \\
\hline & $\mathrm{T} 4$ & 2.351 & 3.001 & 0.103 \\
\hline \multirow{4}{*}{$\mathrm{NH}_{2}$} & Top & -4.325 & 1.981 & 0.022 \\
\hline & Bridge & -3.781 & 2.031 & 0.211 \\
\hline & $\mathrm{H} 3$ & -3.564 & 2.001 & 0.199 \\
\hline & $\mathrm{T} 4$ & -2.961 & 2.155 & 0.200 \\
\hline \multirow{4}{*}{$\mathrm{NH}$} & Top & -5.784 & 1.699 & 0.054 \\
\hline & Bridge & -6.436 & 0.556 & 0.034 \\
\hline & H3 & -5.011 & 1.800 & 0.061 \\
\hline & $\mathrm{T} 4$ & -5.013 & 1.801 & 0.059 \\
\hline \multirow{4}{*}{$\mathrm{N}$} & Top & -7.011 & 1.021 & none \\
\hline & Bridge & -6.787 & 1.313 & none \\
\hline & H3 & -6.996 & 0.997 & none \\
\hline & $\mathrm{T} 4$ & -7.353 & 0.972 & none \\
\hline
\end{tabular}

Table 3. Structure parameters, stable adsorption sites at $\mathrm{NH}_{\mathrm{n}}$ adsorbed on the AlN (0001) surface and the corresponding adsorption energies. $E_{a d}$ represents the adsorption energy. $d_{N-\text { surf }}$ represents the average distance of $\mathrm{N}$ atoms of $\mathrm{NH}_{\mathrm{n}}$ with the surface atoms. $\theta$ represents the angle between the $\mathrm{NH}_{\mathrm{n}}$ and the AlN (0001) surface.

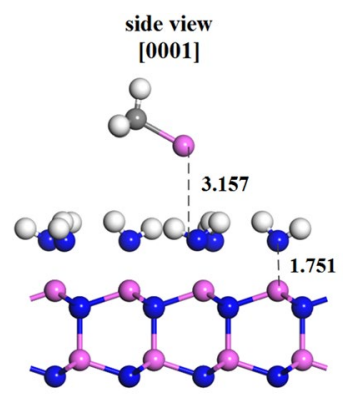

(a)

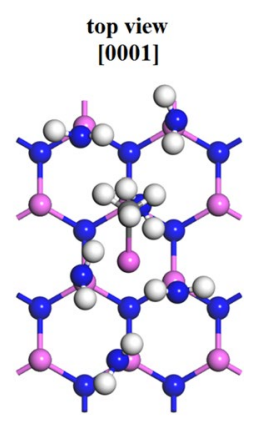

(b)

Figure 5. (a) Side-view and (b) Top-view of $(2 \times 2)$ slab model of reconstructed AlN (0001) surface, where pink, blue and white spheres denote aluminum, nitrogen and hydrogen atoms, respectively. The digital signs show the distance from $\mathrm{AlCH}_{3}$ to the $\mathrm{NH}_{2}$ coverage layers and the distance from the $\mathrm{NH}_{2}$ coverage layers to the AlN (0001) surface, the unit is $\AA$.

$$
N H=N+H
$$

The obtained decomposition energy for reactions (2), (3) and (4) were 2.01, 3.59 and $1.61 \mathrm{eV}$, respectively. Therefore, the values of the reaction energies of $\mathrm{NH}_{3}, \mathrm{NH}_{2}, \mathrm{NH}$ and $\mathrm{N}$ adsorption on the surface are 1.926, $-2.315,-0.836,-0.143 \mathrm{eV}$, respectively. This result suggests that $\mathrm{NH}_{2}$ is the most favorable adsorption species and on the top site is the most stable when the decomposition of $\mathrm{NH}_{3}$ is considered.

Adsorption of group-III source on reconstructed AIN (0001) surface. Since surface reconstructions affect the crystals morphology and play an important role to fabricate high-quality crystals, understanding surface reconstructions is an important issue ${ }^{21,22}$. The adsorption on $\mathrm{AlN}$ (0001) surface under N-rich conditions is much easier than that under $\mathrm{H}$-rich conditions, which the $\mathrm{N}$-rich and $\mathrm{H}$-rich conditions refer to the $\mathrm{N}$ atom and $\mathrm{H}$ atom coverage on the surface ${ }^{10}$. On the results of decomposition and adsorption of group $\mathrm{V}$ source on AlN (0001) surface, we investigate the adsorption on reconstruction AlN (0001) surface with $\mathrm{NH}_{2}$ as coverage source. The structure that $\mathrm{AlCH}_{3}$ molecule adsorb to reconstructed $\mathrm{AlN}$ (0001) surface (shown in Fig. 5) was optimized and the adsorption energy was calculated. As shown in the Fig. 5, we can see that the $\mathrm{AlCH}_{3}$ moved from top site to h3 site, and the distance from $\mathrm{AlCH}_{3}$ to the reconstructed AlN (0001) surface is $3.157 \AA$ larger than that on the $\mathrm{AlN}$ (0001) surface. Meanwhile, the optimized adsorption energy of $\mathrm{AlCH}_{3}$ molecule is $5.78 \mathrm{eV}$, indicating 


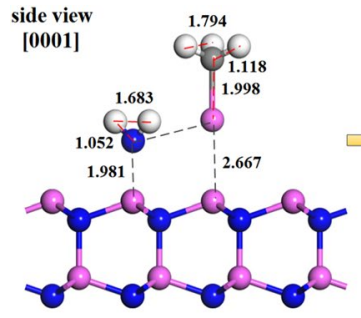

(a)

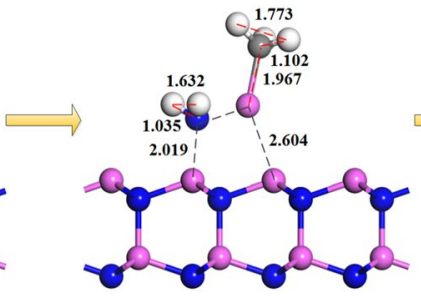

(b)

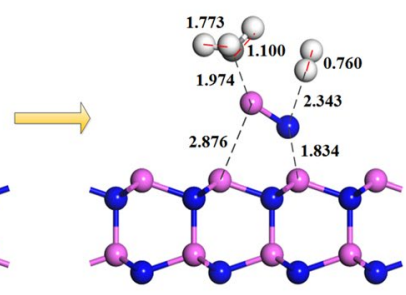

(c)

Figure 6. The desorption process of $\mathrm{AlCH}_{3}$ and $\mathrm{NH}_{2}$ molecules on the $\mathrm{AlN}$ (0001) surface; (a) Initial adsorption, (b) Stable adsorption and (c) Desorption state, where pink, blue and white spheres denote aluminum, nitrogen and hydrogen atoms, respectively. The digital signs show the distances, the unit is $\AA$.

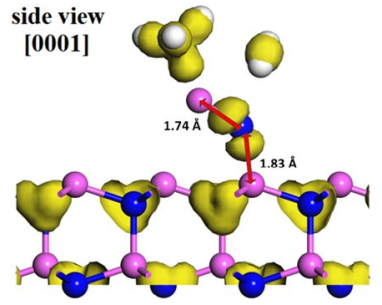

Figure 7. The difference charge density of the initial growth modeling on AlN(0001) surface after the desorption path (5). Yellow regions represent larger charge density.

that the adsorption process requires heat which is not stable on reconstructed $\mathrm{AlN}$ (0001) surface. Al atom in $\mathrm{AlCH}_{3}$ molecule is not bonded with the $\mathrm{N}$ and $\mathrm{H}$ atoms in $\mathrm{NH}_{2}$ the surface covering layer. While The $\mathrm{N}$ atom in each $\mathrm{NH}_{2}$ molecule in the covering layer forms a $\mathrm{Al}-\mathrm{N}$ covalent bond with $\mathrm{Al}$ atom on the top site of topmost surface, but the covalency is very weak. These results indicate that the $\mathrm{NH}_{2}$ coverage layer have a repulsion effect to $\mathrm{AlCH}_{3}$ molecule adsorption. There is a research has shown that $\mathrm{H}$ atoms tend to desorb from AlN (0001) surface even under high $\mathrm{H}_{2}$ pressures ${ }^{37}$, and Toru Akiyama et al. reported, the $\mathrm{N}$ atoms coverage layer is easier to promote the growth of AlN on AlN (0001) surface than that of $\mathrm{H}$ atoms during the MOVPE ${ }^{10}$. In summary, we have found that when $\mathrm{N}$ and $\mathrm{H}$ atoms cover the surface in the form of $\mathrm{NH}_{2}$ molecular structure, they will inhibit the adsorption of $\mathrm{Al}$ source on $\mathrm{AlN}$ (0001) surface, which also indicated that the desorption of $\mathrm{H}$ atom has a greater impact on the initial surface growth process on AlN (0001) surface than the adsorption of $\mathrm{N}$ atom.

Desorption path of group-III and group-V sources on AIN surface. Our study shows that the adsorption of group-III and group-V sources on the AlN (0001) surface is in the form of $\mathrm{AlCH}_{3}$ and $\mathrm{NH}_{2}$, and the stable adsorption site is top site. In order to established the surface growth model of AlN film, we also modeled the desorption process of group-III and group-V sources on the AlN (0001) surface. The model for the desorption path of group-III and group-V sources on AlN (0001) surface were performed as $\mathrm{AlCH}_{3}$ and $\mathrm{NH}_{2}$, and the results are shown in Fig. 6. The reaction path (5) shows the optimized desorption path after the $\mathrm{AlCH}_{3}$ and $\mathrm{NH}_{2}$ molecules adsorbed on AlN (0001) surface top site.

$$
\operatorname{MMAl}(\mathrm{S})+\mathrm{NH}_{2}\left(\mathrm{~S} \rightarrow \mathrm{AlN}(\mathrm{B})+\mathrm{OPENA}(\mathrm{S})+\mathrm{OPENN}(\mathrm{S})+\mathrm{CH}_{3}+\mathrm{H}_{2}\right.
$$

where the $\mathrm{MMAl}(\mathrm{S})$ and $\mathrm{NH}_{2}(\mathrm{~S})$ refer to the adsorbed $\mathrm{AlCH}_{3}$ and $\mathrm{NH}_{2}$ molecules on $\mathrm{AlN}$ (0001) surface top site. The AlN(B) represents the AlN molecule adsorbed on the topmost on AlN (0001) surface after the desorption process. The OPENA(S) and OPENN(S) are open aluminum and nitrogen sites, respectively. $\mathrm{The}^{\mathrm{CH}} \mathrm{H}_{3}$ and $\mathrm{H}_{2}$ are the desorption products.

The energy of reaction path (5) is $2.261 \mathrm{eV}$. First, the $\mathrm{AlCH}_{3}$ and $\mathrm{NH}_{2}$ molecules adsorbed on AlN (0001) surface top site, as shown in Fig. 6a. Second, due to the molecular interaction, the molecules stable adsorption sites will be optimized, as shown in Fig. 6b. Finally, the desorption path is the demethylation of $\mathrm{AlCH}_{3}$ and dehydrogenation of $\mathrm{NH}_{2}$, which the $\mathrm{CH}_{3}$ and $\mathrm{H}_{2}$ in the gas phase, as shown in Fig. $6 \mathrm{c}$. The charge difference diagram is shown in Fig. 7. The $\mathrm{Al}$ atom in $\mathrm{AlCH}_{3}$ molecule and $\mathrm{N}$ atom in $\mathrm{NH}_{2}$ form a Al-N covalent bond with value of $1.74 \AA$ (arrow in Fig. 7), which is shorter than the Al-N bond on AlN (0001) surface. In addition, the $\mathrm{N}$ atom in $\mathrm{NH}_{2}$ and $\mathrm{Al}$ atom on the top site of topmost surface forms a Al-N covalent bond with value of $1.83 \AA$ (arrow in Fig. 7). Therefore, we proposed the surface growth model on AlN (0001) surface as follows: after $\mathrm{AlCH}_{3}$ and $\mathrm{NH}_{2}$ molecules adsorbed on the top site respectively, they will be follow the desorption path (5) and the initial bonding process is given. 


\section{Conclusions}

In summary, the adsorption, decomposition and desorption process of group-III and group-V sources on AlN surfaces during MOCVD growth were investigated using density-functional ab initio calculations in molecularscale. We have found that $\mathrm{AlCH}_{3}$ and $\mathrm{NH}_{2}$ molecules prefer to be adsorbed on AlN (0001) surface on the top site. By the study of the adsorption on reconstruction AlN (0001) surface, it follows that $\mathrm{AlCH}_{3}$ molecules growth to be prominent under ideal surface rather than $\mathrm{NH}_{2}$-rich conditions. Moreover, we have proposed the desorption path of the group-III and group-V sources on AlN (0001) surface. To sum up, the study in this paper explained the molecular-scale surface growth mechanism of AlN during MOCVD, and established the surface growth model on AlN (0001) surface. The results are helpful for the future calculation concerning more detailed growth process of AlN process during MOCVD growth.

Received: 21 February 2020; Accepted: 28 August 2020

Published online: 20 October 2020

\section{References}

1. Pan, L., Dong, X., Li, Z., Luo, W. \& Ni, J. Influence of the AlN nucleation layer on the properties of AlGaN/GaNheterostructure on Si ( $\left.\begin{array}{lll}1 & 1 & 1\end{array}\right)$ substrates. Appl. Surf. Sci. 447, 512-517 (2008).

2. Chyurlia, P. et al. Monolithic integration of AlGaN/GaNHFET with MOS on silicon (111) substrates. IEEE Electron. Lett. 46, 253-254 (2010).

3. Lenci, S. et al. Au-Free AlGaN/GaN power diode on 8-in Si substrate with gated edge termination. IEEE Electron. Dev. Lett. 34, 1035-1037 (2013).

4. Dadgar, A. et al. Thick, crack-free blue light-emitting diodes on Si(111) using low-temperature AlN interlayers and in situ SixNy masking. Appl. Phys. Lett. 80, 3670 (2002).

5. Arulkumaran, S., Egawa, T., Matsui, S. \& Ishikawa, H. Enhancement of breakdown voltage by AlN buffer layer thickness in AlGaN/GaN high-electron-mobility transistors on 4in diameter silicon. Appl. Phys. Lett. 86, 123503 (2005).

6. Wu, M. et al. Effect of the N/Al ratio of AlN buffer on the crystal properties and stress state of GaN film grown on Si(1 11$)$ substrate. Cryst. Growth. 260, 331-335 (2004).

7. Yu, X., Ni, J., Li, Z., Zhou, J. \& Kong, C. Reduction in leakage current in AlGaN/GaNHEMT with three Al-containing step-graded AlGaN buffer layers on silicon. Jpn. J. Appl. Phys. 53, 051001 (2014).

8. Visalli, D. et al. Experimental and simulation study of breakdown voltage enhancement of AlGaN/GaNheterostructures by Si substrate removal. Appl. Phys. Lett. 97, 113501 (2010).

9. Bak, S. J. et al. Effect of Al pre-deposition on AlN buffer layer and GaN film grown on Si (111) substrate by MOCVD. Electron. Mater. Lett. 9, 367-370 (2013).

10. Akiyama, T., Nakamura, K. \& Ito, T. Ab initio-based study for adatom kinetics on AlN(0001) surfaces during metal-organic vaporphase epitaxy growth. Appl. Phys. Lett. 100, 251601 (2012).

11. Sangiovanni, D. G., Gueorguiev, G. K. \& Kakanakova-Georgieva, A. Phys. Chem. Chem. Phys. 20, 17751-17761 (2018).

12. Adelmann, C. et al. Gallium adsorption on (0001) GaN surfaces. Phys. Rev. B. 67, 165419 (2003).

13. Dasgupta, S., Wu, F., Speck, J. S. \& Mishra, U. K. Growth of high quality N-polar AlN(000-1) on Si(111) by plasma assisted molecular beam epitaxy. Appl. Phys. Lett. 94, 151906 (2009).

14. Fritsch, J., Sankey, O. F., Schmidt, K. E. \& Page, J. B. Ab initio calculation of the stoichiometry and structure of the (0001) surfaces of GaN and AlN. Phys. Rev. B. 57, 15360 (1998).

15. Fujimoto, N. et al. Growth of high-quality AlN at high growth rate by high-temperature MOVPE. Phys. Status Solidi C. 3, 1617-1619 (2006).

16. Johnson, M. A. L. et al. Molecular beam epitaxy growth and properties of $\mathrm{GaN}, \mathrm{Al}_{\mathrm{x}} \mathrm{Ga}_{1-\mathrm{x}} \mathrm{N}$, and $\mathrm{AlN}$ on $\mathrm{GaN} / \mathrm{SiC}$ substrates. J. Vac. Sci. Technol. B. 14, 2349-2353 (1996).

17. Kumagai, Y., Yamane, T. \& Koukitu, A. Growth of thick AlN layers by hydride vapor-phase epitaxy. J. Cryst. Growth. 281, 62-67 (2005).

18. Lee, C. D., Dong, Y., Feenstra, R. M., Northrup, J. E. \& Neugebauer, J. Reconstructions of the AlN(0001) surface. Phy. Rev. B. 68, 205317 (2003).

19. Liu, Y.-H. et al. Growth of Thick AlN Layer by Hydride Vapor Phase Epitaxy. Jpn. J. Appl. Phys. Part 2(44), L505-507 (2005).

20. Miyagawa, R., Yang, S., Miyake, H. \& Hiramatsu, K. Effects of carrier gas ratio and growth temperature on MOVPE growth of AlN. Phys. Status Solidi C 9, 499-502 (2012).

21. Kadas, K., Alvarez, S., Ruiz, E. \& Alemany, P. Structure of the non-polar (1010) surfaces of AlN and a-SiC: A periodic Hartree-Fock study. Surf. Sci. 355, 167-176 (1996).

22. Akiyama, T., Obara, D., Nakamura, K. \& Ito, T. Reconstructions on AlN polar surfaces under hydrogen rich conditions. Jpn. J. Appl. Phys. 51, 018001 (2012).

23. Uchida, T., Kusakabe, K. \& Ohkawa, K. Influence of polymer formation on metalorganic vapor-phase epitaxial growth of AlN. J. Cryst. Growth. 304, 133-140 (2007).

24. Blöchl, P. E. Projector augmented-wave method. Phys. Rev. B. 50, 17953-17979 (1994)

25. Kresse, G. From ultrasoft pseudopotentials to the projector augmented-wave method. Phys. Rev. B. 59, 1758-1775 (1999).

26. Suzuki, H., Togashi, R., Murakami, H., Kumagai, Y. \& Koukitu, A. G Ab initio calculation for an initial growth process of GaN on (0001) and (000-1) surfaces by vapor phase epitaxy. Phys. Status Solidi C. 52, s301-s304 (2009).

27. Kresse, G. \& Furthmüller, J. Efficient iterative schemes for ab initio total-energy calculations using a plane-wave basis set. Phys. Rev. B. 54, 11169-11186 (1996).

28. Ceperley, D. M. \& Alder, B. J. Ground state of the electron gas by a stochastic method. Phys. Rev. Lett. 45, 566-569 (1980).

29. Perdew, J. P. \& Wang, Y. Accurate and simple analytic representation of the electron-gas correlation energy. Phys. Rev. B. 45, 13244-13249 (1992).

30. Soler, J. et al. The SIESTA method for ab initio order-N materials simulation. J. Phys. Condens. Matter. 14, 2745-2779 (2002).

31. Perdew, J. P., Burke, K. \& Ernzerhof, M. Generalized gradient approximation made simple. Phys. Rev. Lett. 77, 3865-3868 (1996).

32. Monkhorst, J. \& Pack, D. Special points for Brillouin-zone integrations. Phys. Rev. B. 13, 5188-5192 (1976).

33. Phatak, A. A., Delgass, W. N., Ribeiro, F. H. \& Schneider, W. F. Density functional theory comparison of water dissociation steps on Cu, Au, Ni, Pd, and Pt. J. Phys. Chem. C. 113, 7269-7276 (2009).

34. Saib, S. \& Bouarissa, N. Structural properties of AlN from first principles calculations. Eur. Phys. J. B. 47, 379-383 (2005).

35. Wei, J. et al. First-principles investigation of water adsorption on FeCrAl (1 110$)$ surfaces. Appl. Surf. Sci. 465, 259-266 (2019).

36. Guo, L. Q., Zhao, X. M., Bai, Y. \& Qiao, L. J. Water adsorption behavior on metal surfaces and its influence on surface potential studied by in situ SPM. Appl. Surf. Sci. 258, 9087-9091 (2012).

37. Mastail, C., David, M., Nita, F., Michel, A. \& Abadias, G. Ti, Al and $\mathrm{N}$ adatom adsorption and diffusion on rocksalt cubic AlN (001) and (011) surfaces: Ab initio calculations. Appl. Surf. Sci. 423, 354-364 (2017). 
38. Mihopoulos, T. G., Gupta, V. \& Jensen, K. F. A reaction-transport model for AlGaNMOVPE growth. J. Cryst. Growth 195, 733-739 (1998).

39. Nakamura, K., Makino, O., Tachibana, A. \& Matsumoto, K. Quantum chemical study of parasitic reaction in III-V nitride semiconductor crystal growth. J. Organometall. Chem. 2, 514-524 (2000).

\section{Acknowledgements}

This work was supported by the National Key R\&D Program of China (Grant No. 2017YFB0404202).

\section{Author contributions}

J.A. wrote the main manuscript text and X.D., R.G. prepared tables 1-2 and L.F., T.Z. prepared figures 1-3. All authors reviewed the manuscript.

\section{Competing interests}

The authors declare no competing interests.

\section{Additional information}

Correspondence and requests for materials should be addressed to X.D.

Reprints and permissions information is available at www.nature.com/reprints.

Publisher's note Springer Nature remains neutral with regard to jurisdictional claims in published maps and institutional affiliations.

(c) (i) Open Access This article is licensed under a Creative Commons Attribution 4.0 International

License, which permits use, sharing, adaptation, distribution and reproduction in any medium or format, as long as you give appropriate credit to the original author(s) and the source, provide a link to the Creative Commons licence, and indicate if changes were made. The images or other third party material in this article are included in the article's Creative Commons licence, unless indicated otherwise in a credit line to the material. If material is not included in the article's Creative Commons licence and your intended use is not permitted by statutory regulation or exceeds the permitted use, you will need to obtain permission directly from the copyright holder. To view a copy of this licence, visit http://creativecommons.org/licenses/by/4.0/.

(C) The Author(s) 2020 